\title{
The Comparison of Adipose Stem Cell and Placental Stem Cell in Secretion Characteristics and in Facial Antiaging
}

\author{
Yan Xu, ${ }^{1,2}$ Shilei Guo, ${ }^{1,2}$ Cui Wei, ${ }^{1}$ Honglan Li, ${ }^{1}$ Lei Chen, ${ }^{1}$ \\ Chang Yin, ${ }^{1}$ and Chuansen Zhang $^{2}$ \\ ${ }^{1}$ Nanjing Regenerative Medicine Engineering and Technology Research Center, Nanjing 210046, China \\ ${ }^{2}$ Regenerative Medicine Center, The Second Military Medical University, Shanghai 200433, China
}

Correspondence should be addressed to Chuansen Zhang; chuansenzhang@sina.com

Received 9 October 2015; Revised 15 December 2015; Accepted 10 January 2016

Academic Editor: Yaoliang Tang

Copyright (C) 2016 Yan Xu et al. This is an open access article distributed under the Creative Commons Attribution License, which permits unrestricted use, distribution, and reproduction in any medium, provided the original work is properly cited.

\begin{abstract}
Background. Mesenchymal stem cells are the most commonly used seed cells in biomedical research and tissue engineering. Their secretory proteins have also been proven to play an important role in tissue healing. Methods. We isolated adipose stem cells and placental stem cells and performed analysis examining characteristics. The secretory proteins were extracted from conditioned medium and analyzed by MALDI-TOF/TOF. The antiaging effect of conditioned mediums was evaluated by the results of facial skin application. Results. Adipose stem cells and placental stem cells were found to be very similar in their surface markers and multipotency. The specific proteins secreted from adipose stem cells were more adept at cell adhesion, migration, wound healing, and tissue remodeling, while the proteins secreted by placental stem cells were more adept at angiogenesis, cell proliferation, differentiation, cell survival, immunomodulation, and collagen degradation. While these two types of conditioned medium could improve the facial index, the improvement of Melanin index after injection of the adipose stem cell conditioned medium was much more significant. Conclusion. The results suggest that the secreted proteins are ideal cell-free substances for regeneration medicine, especially in the antiaging field.
\end{abstract}

\section{Introduction}

Mesenchymal stem cells are a type of adult stem cell with the attributes of self-renewing and multipotency. They can be used in biomedical research, new drug development, and toxicology studies, and so forth [1]. Currently this type of cell is a focal point in clinical research and application [2-4].

The phenomenon that mesenchymal stem cells could improve distal injury organ healing without cell migration and cell differentiation indicates that the cell exosomes play an important role in tissue and organ repair [5-7]. In addition to cell differentiation and proliferation, the secreted proteins also represent an important extension of the stem cells' function $[8,9]$.

In recent years, adipose stem cells (ASCs) have received great attention in regenerative medicine. The research shows that ASCs are both abundant and varying in activities within our bodies [10]. The ASCs also have very similar characteristics and classification with bone marrow mesenchymal stem cells. Therefore, the proliferation, differentiation, and secretome characteristics of ASCs are considered advantageous in tissue protection, antiapoptosis, and cell replacement [11]. In addition, fat tissue is easily harvested in plastic surgery, making ASC an accessible and ideal kind of adult stem cell.

ASCs have the problem of being limited in cosmetics and clinical application. Due to the requirement of having a large quantity for clinical application, we also chose to use placental stem cells (PSCs) in this secretomics research [12]. Placental tissue is a crucial accessory in protection, nutrition, respiration, and excretion of the embryo. Researchers isolated mesenchymal stem cells from mature placenta and found that PSCs express the typical genes of mesenchymal stem cells as well as some other specific gene [13]. In addition, the placenta is an important nutrient for the development of the fetus and can secrete many developmental factors, such as granulocyte colony-stimulating factor (G-CSF), granulocyte-macrophage colony-stimulating factor 
(GM-CSF), macrophage colony-stimulating factor (M-CSF), and stem cell factor (SCF) [14]. From this, we speculate that PSCs have unique characteristic of their secretome.

The characterization of secretomics of mesenchymal stem cells was unclear because of the differences in culture condition, culture medium, expansion time, and so forth. In our research, we utilized a method for the extraction of secretory proteins suitable for clinical application and analysis of the secretomes of ASCs and PSCs. Furthermore, we examined the antiaging ability of their secretion factors in human facial skin.

\section{Methods}

The human trials in this study obtained the informed consent of the volunteers according to the Helsinki Declaration and were approved by the Society of Medical Ethics in Jiangsu Province.

2.1. Isolation of Adipose Stem Cells and Placental Stem Cells. A single sample of $100 \mathrm{~mL}$ of adipose tissue was first harvested from a 45-year-old female cosmetic surgery patient. The adipose tissue was washed three times with sterile phosphatebuffered saline solution (PBS). The washed tissue was cut into pieces and digested by collagenase (type I collagenase, Worthington, USA) for forty minutes at $37^{\circ} \mathrm{C}$ with gentle agitation. Enzyme activity was neutralized with Dulbecco Modified Eagle Medium (DMEM) supplemented with 2\% fetal bovine serum (FBS), and the tissues were filtered with $150 \mu \mathrm{m}$ filters. After centrifugation at $300 \mathrm{~g}$ for 10 minutes, the cell pellet was resuspended in DMEM containing 2\% human platelet lysate (hPL) and $1 \%$ penicillin-streptomycin, cultured, and expanded at $37^{\circ} \mathrm{C}$ in $5 \% \mathrm{CO}_{2}$ incubators.

The placental tissue was washed with PBS to remove the blood. The tissue was minced into small pieces and incubated with $0.2 \%$ collagenase II for one hour at $37^{\circ} \mathrm{C}$ to allow for thorough digestion and filtered through a $250 \mu \mathrm{m}$ metal sieve to remove the tissue fragments. The cells were collected by centrifugation at $300 \mathrm{~g}$ for $10 \mathrm{~min}$ and washed three times with PBS. The cell pellet was then suspended in DMEM with $2 \% \mathrm{hPL}$ and $1 \%$ penicillin-streptomycin and incubated at $37^{\circ} \mathrm{C}$ in $5 \% \mathrm{CO}_{2}$ incubators.

2.2. Characteristics of Adipose Stem Cells and Placental Stem Cells. To confirm multipotency, the differentiability of the cells into osteoblasts, adipocytes, and chondrocytes was analyzed. Both types of cells were plated at a density of $3 \times 10^{4}$ cells $/ \mathrm{cm}^{2}$ in dishes at passage 3 . Once the cells were $90 \%$ confluent, the completed medium was substituted with inducing medium (osteogenic medium: completed medium supplemented with $50 \mu \mathrm{M}$ ascorbic acid, $0.1 \mu \mathrm{M}$ dexamethasone, and $10 \mathrm{mM}$ b-glycerolphosphate; adipogenic medium: complete medium supplemented with $1.0 \mu \mathrm{M}$ dexamethasone, $10 \mathrm{mg} / \mathrm{mL}$ insulin, $100 \mu \mathrm{M}$ indomethacin, and $500 \mu \mathrm{M}$ IBMX; chondrogenic medium: completed medium with $1 \%$ penicillin-streptomycin, $1 \%$ ITS (insulin, transferrin, and selenium), $100 \mathrm{nM}$ dexamethasone, $50 \mu \mathrm{g} / \mathrm{mL} \mathrm{L}$-ascorbic acid 2-phosphate, $10 \mathrm{ng} / \mathrm{mL}$ TGF $\beta 1$, and $500 \mathrm{ng} / \mathrm{mL}$ BMP6).
For up to 20 days, the cells were stained with Oil Red O for adipogenic induction, Alizarin Red S for osteogenic induction, or Safranin O for chondrogenic induction. For fluorescence activated cell sorting (FACS) analysis, the cultured cells were collected and incubated with CD29-fluorescein isothiocyanate (FITC), CD34-FITC, CD71-FITC, and CD90FITC for $30 \mathrm{~min}$ at $4^{\circ} \mathrm{C}$ and then analyzed using flow cytometry.

2.3. Extraction of Secretory Protein in Conditioned Medium (CM). The ASCs and PSCs culture dishes were washed three times with PBS and cultured overnight in culture medium consisting of DMEM, Nutrient Mixture F-12 (DMEM/F12 ), and $0.2 \%$ hPL resulting in about $6-8 \times 10^{6}$ cells. After 24 hours, the cultured medium was collected and fresh serum-free medium was added. The CM was filtered using a $0.22 \mu \mathrm{m}$ filter, centrifuged with Amicon Ultra $15 \mathrm{~mL}$ (MWCO $3 \mathrm{kD}$, Millipore) at $4^{\circ} \mathrm{C} 4000 \mathrm{~g}$ for 30 minutes, and then concentrated about 5 times using ultrafiltration membrane of $3.5 \mathrm{kD}$ with polyethylene glycol at $4^{\circ} \mathrm{C}$. Overall, the $\mathrm{CM}$ was concentrated about 15 times in the above process. The initial concentration was $1000 \mathrm{~mL}$ of $0.389 \pm 0.04 \mathrm{mg} / \mathrm{mL}$ and the final concentration was $70 \mathrm{~mL}$ of $5.989 \pm 0.07 \mathrm{mg} / \mathrm{mL}$. Freezedry powder was prepared in sterilized penicillin bottles using the Lyophilizer (Boyikang Corp., Beijing, China).

2.4. MALDI-TOF/TOF Analysis. Protein identification experiments were performed at positive mode using the MALDI-TOF/TOF 7090 system. In-gel tryptic digestion of the proteins was performed using an in-gel digestion kit following the protocol recommended by the manufacturer (Shimadzu Kratos, Kyoto). Before deposition onto a MALDI plate, all samples were desalted and concentrated with C18 ZipTip following the recommended protocol (Millipore, Massachusetts). Peptide extracts were eluted in a concentrated solution of 2,5-dihydroxybenzoic acid $(12.5 \mathrm{mg} / \mathrm{mL})$ with $50 \%$ acetonitrile and $0.1 \%$ trifluoroacetic acid in water and spotted onto the MALDI target plate. The TOF spectra were recorded in the reflector mode with a mass range from 500 to $2000 \mathrm{Da}$. Each spectrum was the cumulative average of 200 laser shots. The spectra were calibrated with the trypsin autodigestion ion peaks $m / z$ (842.51 and 2211.10). The peptide mass fingerprints (PMF) were obtained using the Mascot search engine with a tolerance of $100 \mathrm{ppm}$ and one missed cleavage site.

2.5. Application in Facial Antiaging. 18 young volunteers were randomly divided into 3 groups with 6 in each group: ASCCM group, PSC-CM group, and control group. The CM of ASC or PSC was dissolved into injectable hyaluronic acid (HA) and injected into the facial skin of each person with DermaQueen equipment (Seoul, Korea). The injected depth was $0.1 \mathrm{~mm}$, the interval was about $2 \mathrm{~mm}$, and the volume was $2 \mu \mathrm{L}$ in each point. The ASC-CM group was injected with HA containing $2 \mathrm{mg} / \mathrm{mL}$ ASC-CM, the PSC-CM group was injected with HA containing $2 \mathrm{mg} / \mathrm{mL}$ PSC-CM, and the control group was injected with HA containing $0.2 \%$ hPL. 15 days after injection, the facial skin of each volunteer was tested 


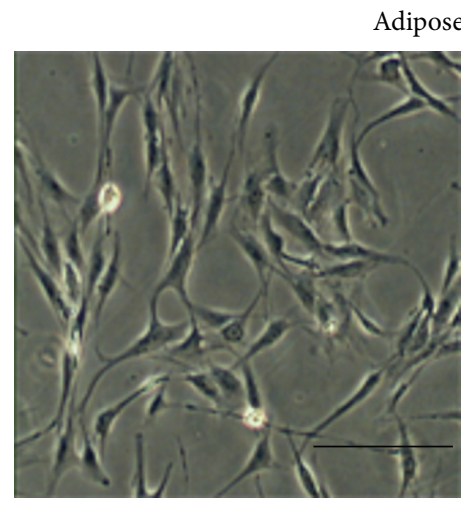

(a1)

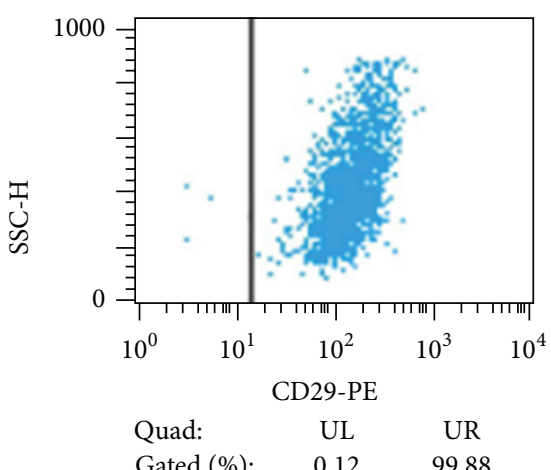

(b1)

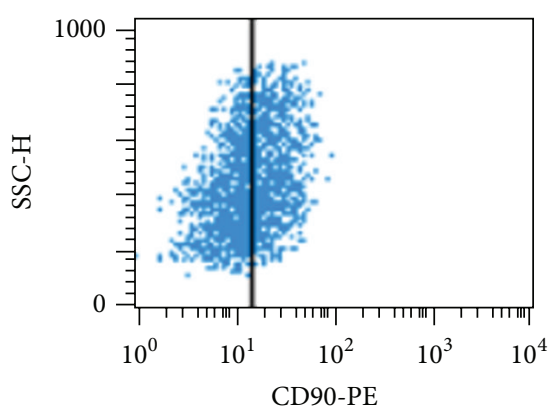

$\begin{array}{lcc}\text { Quad: } & \text { UL } & \text { UR } \\ \text { Gated (\%): } & 52.90 & 47.10\end{array}$

(b4)

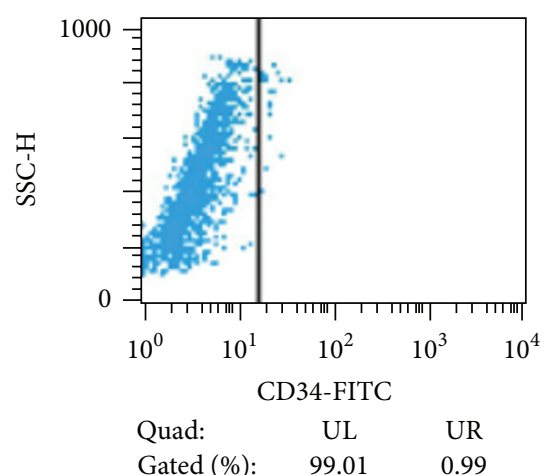

(b2)

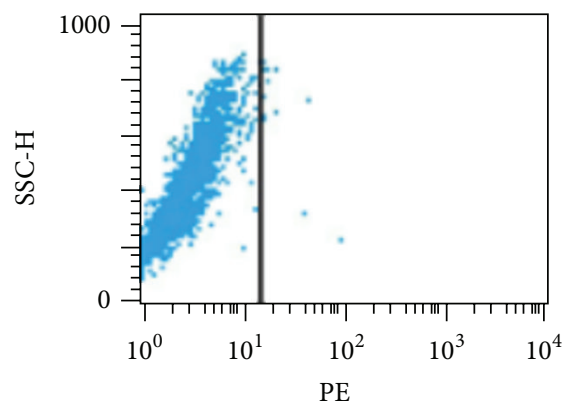

Quad: $\quad$ UL $\quad$ UR

(b5)

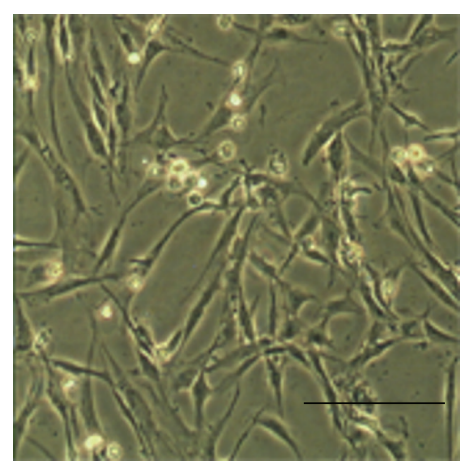

(a2)

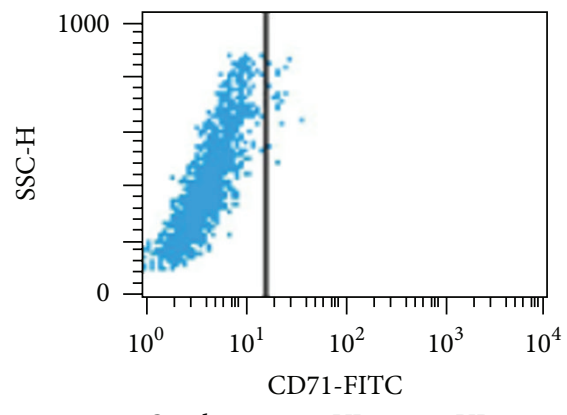

Quad: UL UR Gated (\%): $\quad 98.83 \quad 1.17$

(b3)

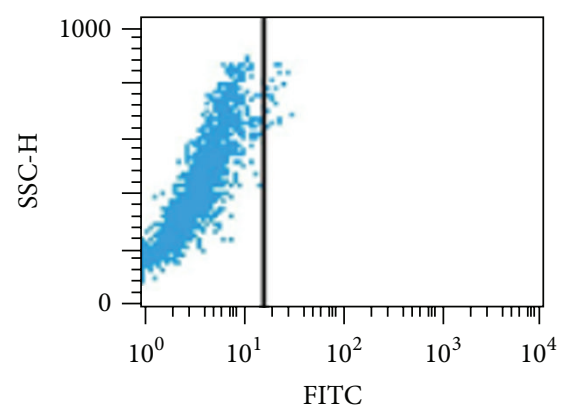

Quad: UL UR

Placenta stem cells

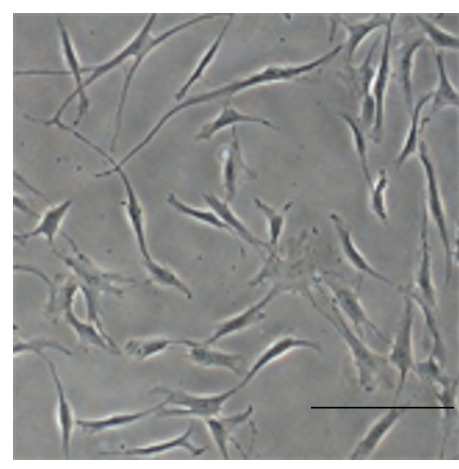

(c1)

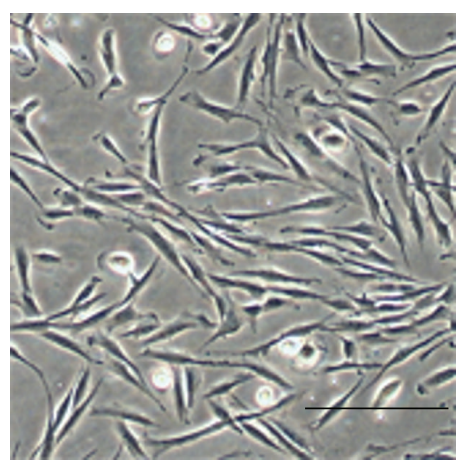

(c2)

FIgUre 1: Continued. 


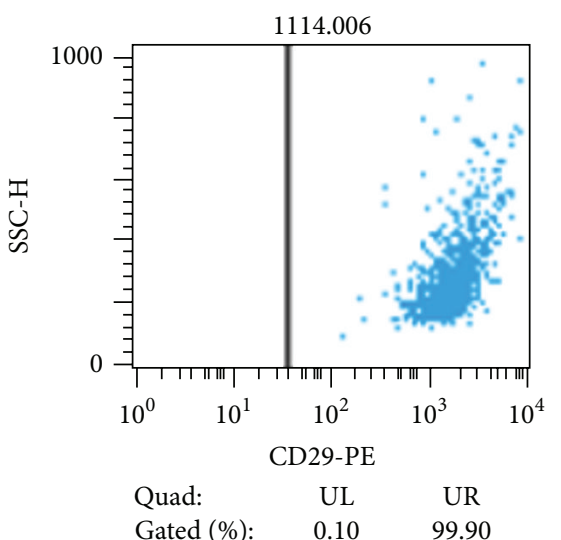

(d1)

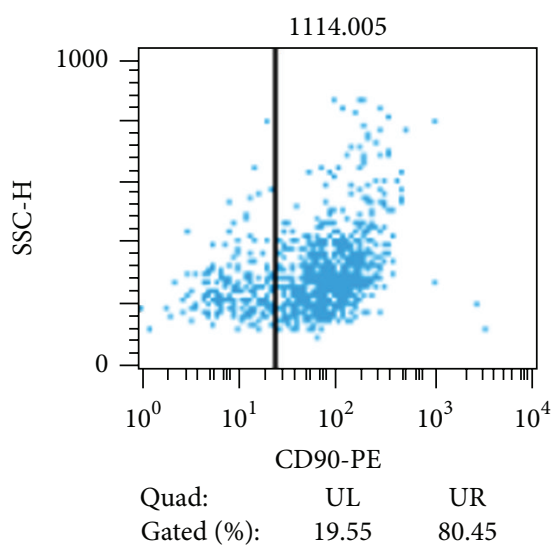

(d4)

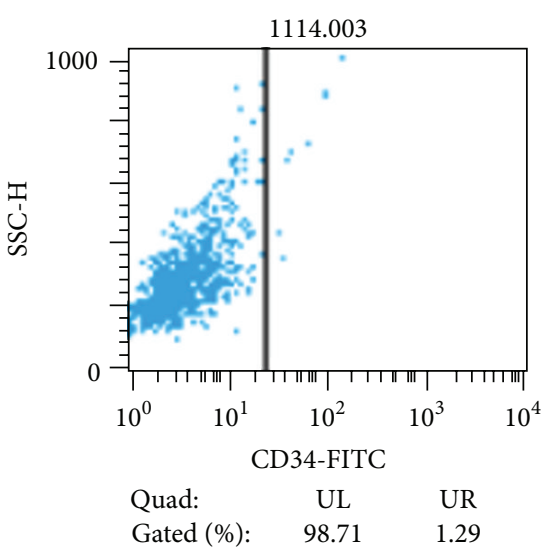

(d2)

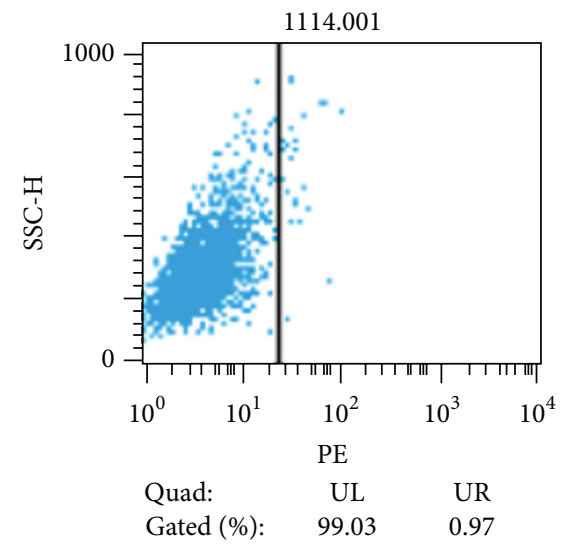

(d5)

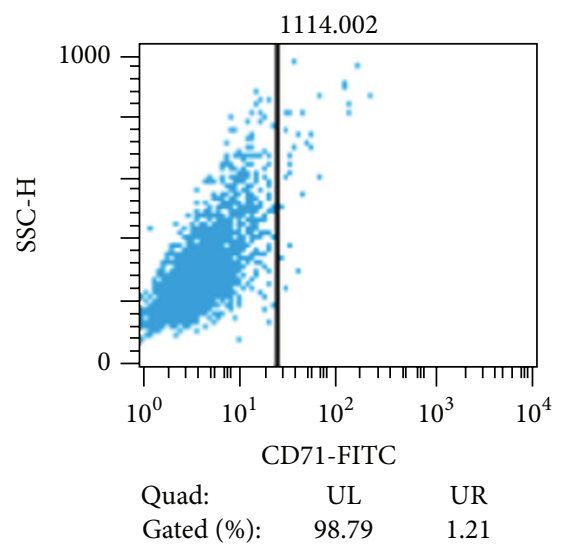

(d3)

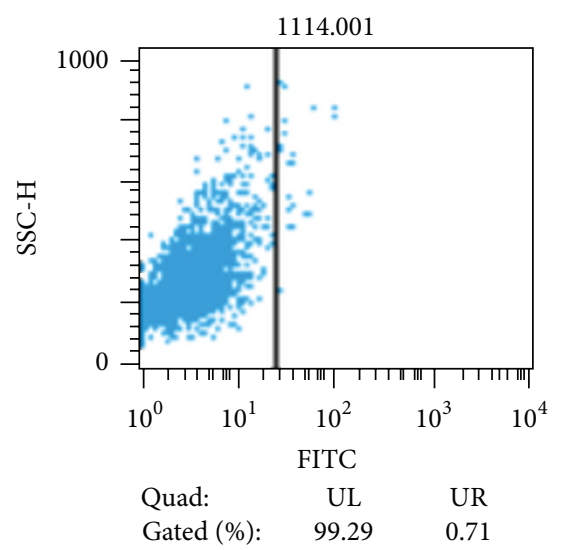

(d6)

FIGURE 1: Characterization of adipose stem cells and placenta stem cells. Both cells showed typical fibroblast-like morphology at passage 1 (al, $\mathrm{c1})$ and passage 3 (a2, c2). The flow cytometry analysis confirmed that adipose stem cells express CD29 (99.88\%, b1) and CD90 (52.9\%, b4) but do not express CD34 (0.99\%, b2) and CD71 (1.17\%, b3); the placenta stem cells express CD29 (99.9\%, d1) and CD90 (80.45\%, d4) but do not express CD34 (1.29\%, d2) and CD71 (1.21\%, d3). The FITC (b6, d6) and PE (b5, d5) were performed as blank control. UL refers to upper left quadrant and UR refers to upper right quadrant. Scale bar $=100 \mu \mathrm{m}$.

with Courage \& Khazaka Electronic GmbH (Cologne, Germany). The detection indexes included Erythema, Melanin, Glossymeter, TEWAmeter, and Corneometer. The intensity of skin redness was measured using the Erythema index (Erythema). The Melanin index represents the darkness of the skin (Melanin). Glossymeter is used to measure gloss on skin. TEWAmeter is used to assess the transepidermal water loss (TEWL) and evaluated the water barrier function of the skin. Corneometer can determine the water content in skin.

2.6. Statistical Analysis. The measurement data was described using mean and standard deviation and the difference was analyzed using paired $t$-test and analysis of variance (ANOVA). All the analyses were performed by Stata $(12.0$ version) using $p<0.05$ as statistically significant.

\section{Results}

3.1. Characterization of Adipose Stem Cells and Placental Stem Cells. ASCs and PSCs showed the same morphological features as fibroblast-like adherent cells in passage 1 and passage 3 (Figure 1). In FACS analysis, the two types of cells expressed the same surface proteins, such as CD29, CD34, and CD71. In this study, the expression of CD90 was $80.45 \%$ in PSC and $47.1 \%$ in ASC (Figure 1). In the multipotency analysis, both types of cells successfully differentiated into chondrocytes, adipocytes, and osteocytes (Figure 2). The experiment showed that these two types of cells have very similar characteristic and function consistent with the characteristics of mesenchymal stem cells.

3.2. Characterization of Secretory Proteins. In our MALDITOF/TOF analysis, 11 proteins were identified in the CM of both types of cells: vascular endothelial growth factor (VEGF), M-CSF, stromal cell-derived factor-1 (SDF-1), transforming growth factor- $\beta$ (TGF- $\beta$ ), tumor necrosis factor- $\alpha$ (TNF- $\alpha$ ), interleukin-1 (IL-1), interleukin-6 (IL-6), hepatocyte growth factor (HGF), insulin-like growth factor-1 (IGF1), metalloproteinase-2 (MMP-2), and interleukin-8 (IL-8) (Table 1). 11 proteins were exclusively identified in the PSCCM: monocyte chemotactic protein 1 (MCP-1) (also referred 


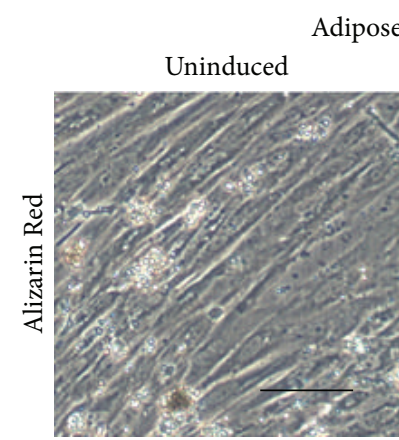

(a1)

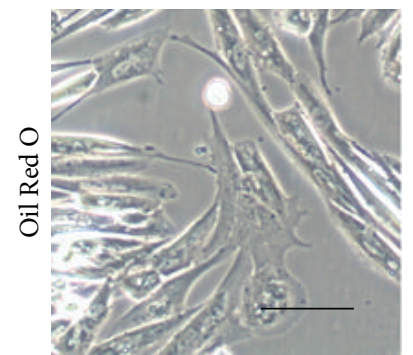

(b1)

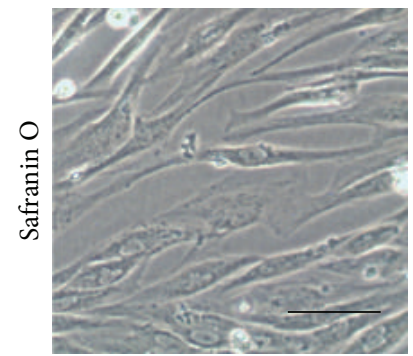

(c1)

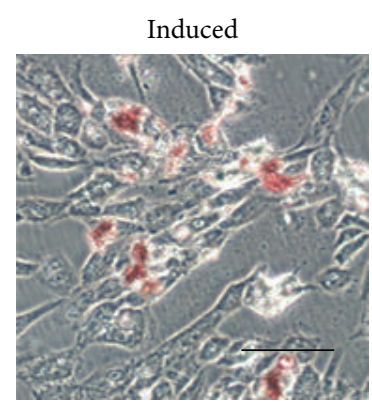

(a2)

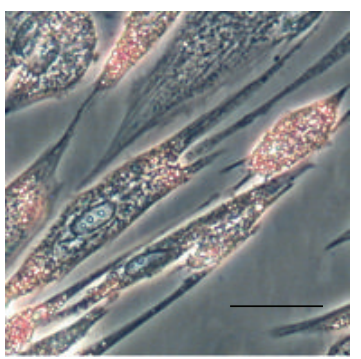

(b2)

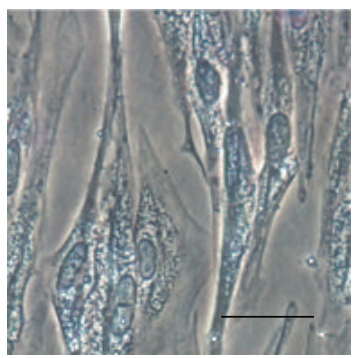

(c2)

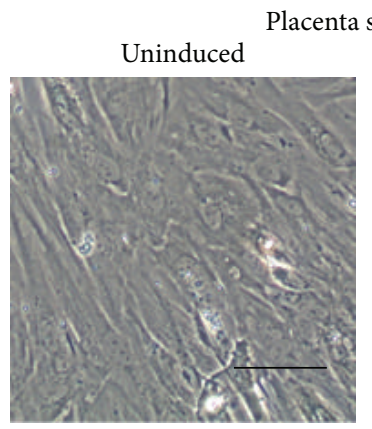

(d1)

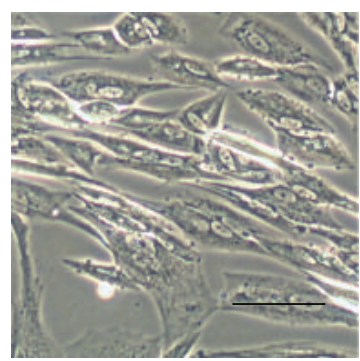

(e1)

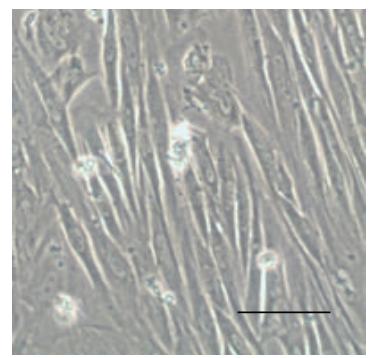

(f1)

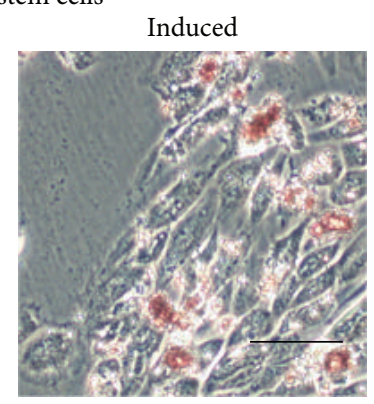

(d2)

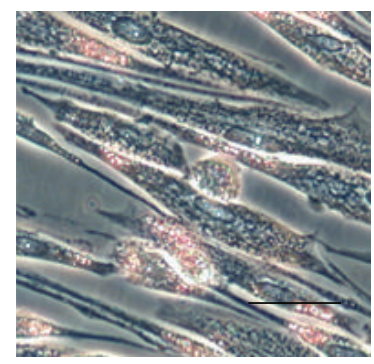

(e2)

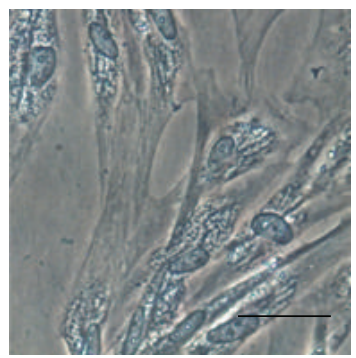

(f2)

Figure 2: Multipotent differentiation of adipose stem cells and placenta stem cells. After 20 days of induction, the cells were stained with Alizarin Red, Oil Red, and Safranin O. Both kinds of cells could differentiate into osteocytes (a2, d2), adipocytes (b2, e2), and chondrocytes $(\mathrm{c} 2, \mathrm{f} 2)$ successfully. And the uninduced groups were cells without induction as negative control (a1-f1). Scale bar $=50 \mu \mathrm{m}$.

to as chemokine ligand 2, CCL2), SCF, basic fibroblast growth factor (FGF-2), fibroblast growth factor 7 (FGF7), angiopoietin-1 (ANGP-1), placental growth factor (PGF), adrenomedullin (AM), plasminogen activator (PA), plateletderived growth factor (PDGF), metalloproteinase-1 (MMP1), and metalloproteinase-9 (MMP-9) (Table 2). 10 proteins were exclusively identified in ASC-CM: acidic fibroblast growth factor (FGF-1), G-CSF, CM-CSF, pigment epitheliumderived factor (PEDF), metalloproteinase inhibitor 1 (TIMP1), plasminogen activator inhibitor (PAI), connective tissue growth factor (CTGF), collagen-1, collagen-6, and fibronectin (FN) (Table 3). The details of peptide sequence identification are shown in Supplement 1 of the Supplementary Material available online at http://dx.doi.org/10.1155/2016/7315830.

According to the molecular function information in the UniProt database, we found that, in the ASC-CM, 52.4\% of total protein types were growth factors, $38.1 \%$ were cytokines, and $19 \%$ were mitogens. In the PSC-CM, $54.5 \%$ of total protein types were growth factors, $31.8 \%$ were cytokines, $31.8 \%$ were mitogens, $22.7 \%$ were development proteins, $18.9 \%$ were proteases, and $18.9 \%$ were hydrolases (Figure 3). Analyzing according to biological processes, we found that in the ASC-CM $19 \%$ of total protein types had angiogenesis function, $14.3 \%$ were involved in inflammatory response, $14.3 \%$ had cell adhesion function, $9.5 \%$ had cell differentiation function, $9.5 \%$ had chemotaxis function, and $9.5 \%$ were involved in acute phase response. In the PSC-CM, $22.7 \%$ of total protein types had angiogenesis function, $18.2 \%$ were involved in inflammatory response, $18.2 \%$ had cell differentiation function, $13.7 \%$ had chemotaxis function, and $13.7 \%$ had collagen degradation function (Figure 3). Almost all of the examined proteins were secreted proteins; some of these proteins are also found in the extracellular matrix, cell membrane, nucleus, and so forth.

The protein-protein interactions of secreted proteins of ASC and PSC were analyzed by STRING 10.0. The interaction network was drawn with the thickness of connecting lines representing the strength of evidence (Figure 4). We found that all proteins could interact with others; some proteins had even more active functions for multiple interaction points. 


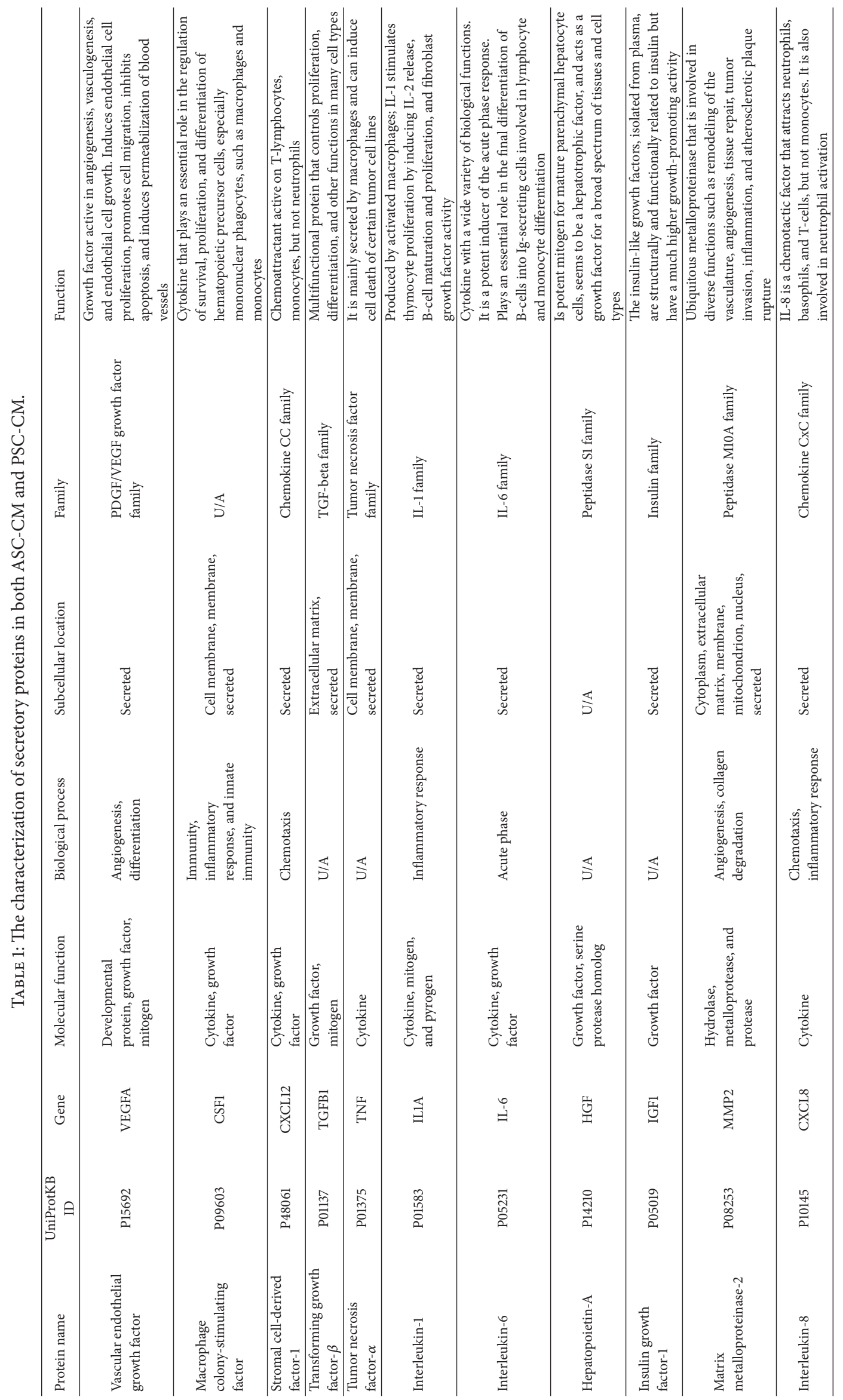




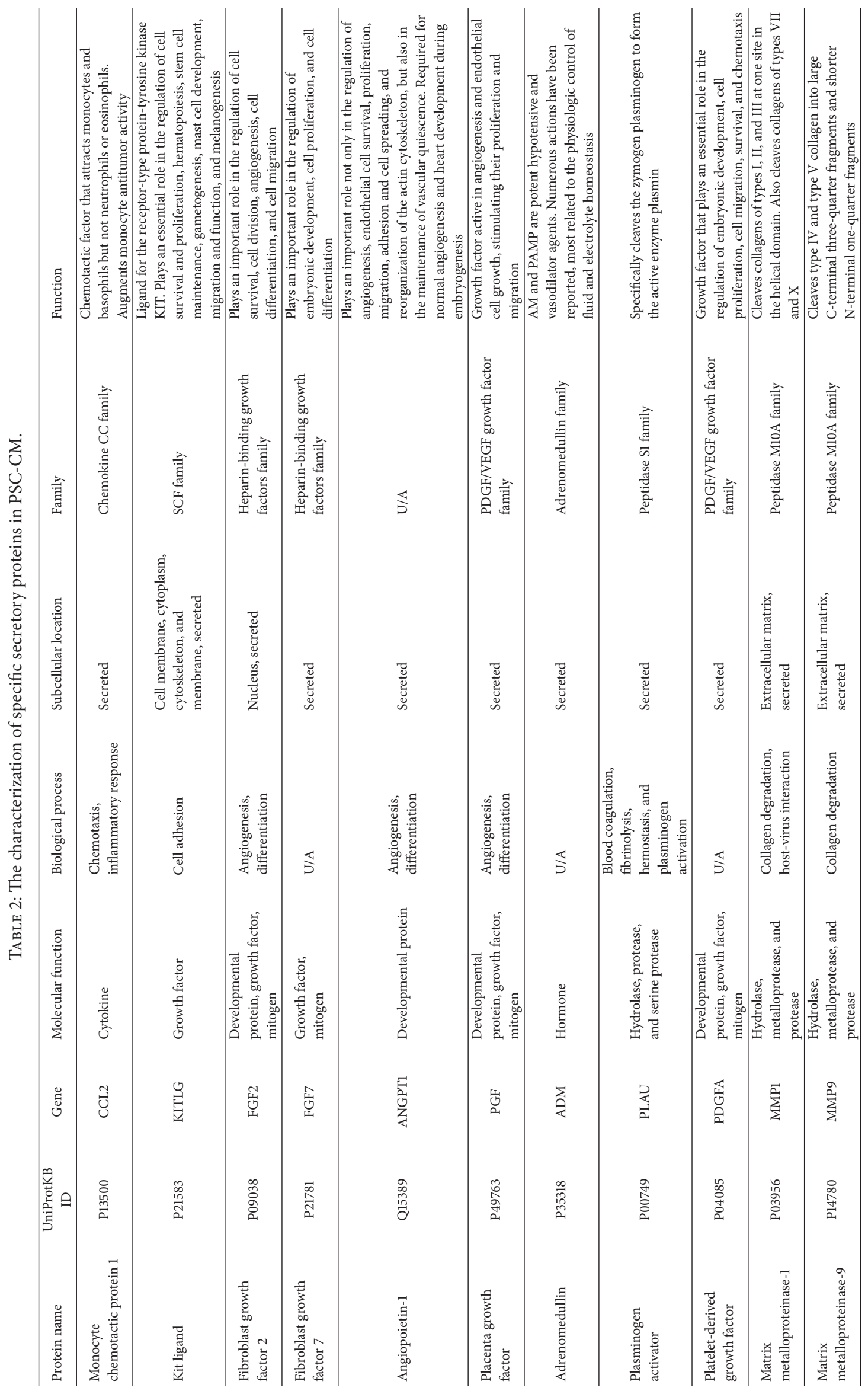




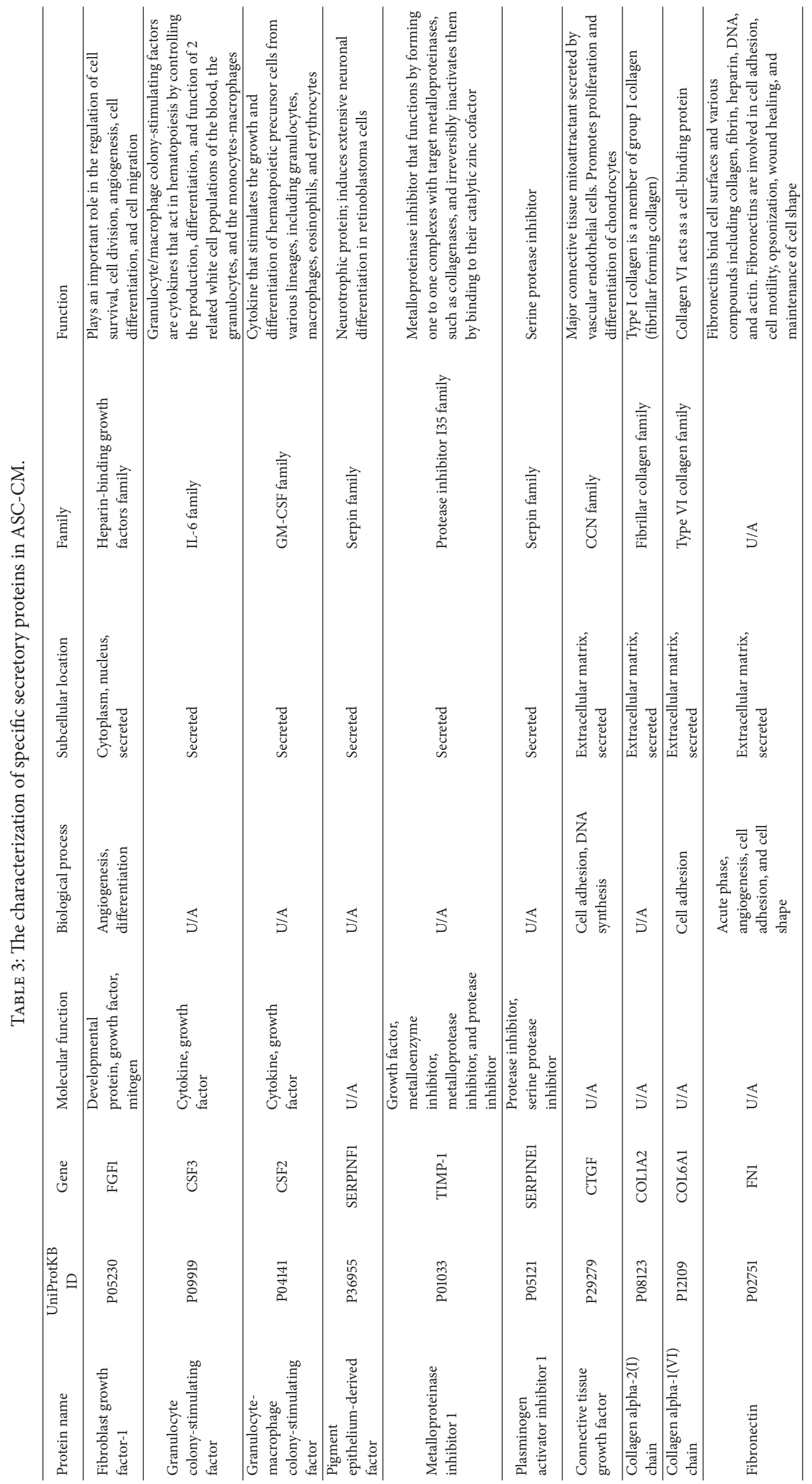




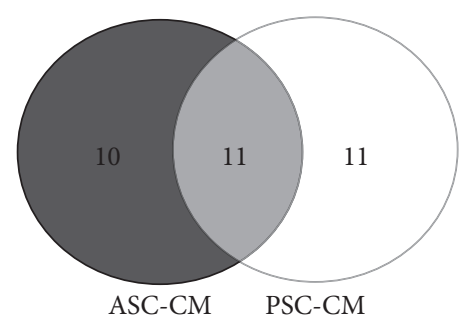

(a)

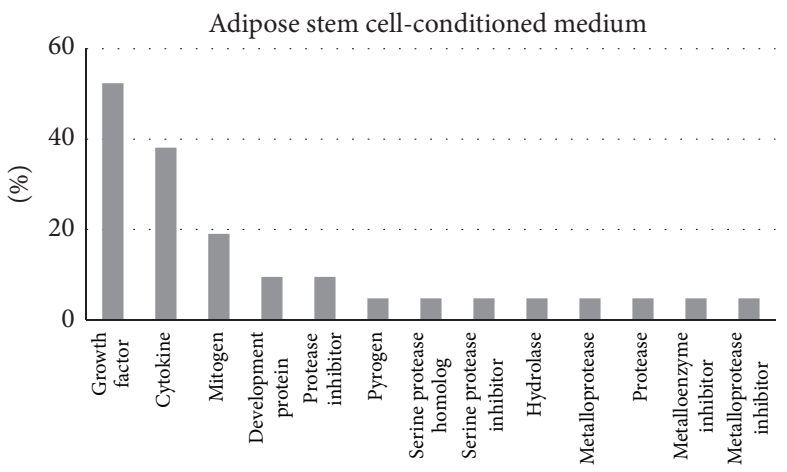

(b1)

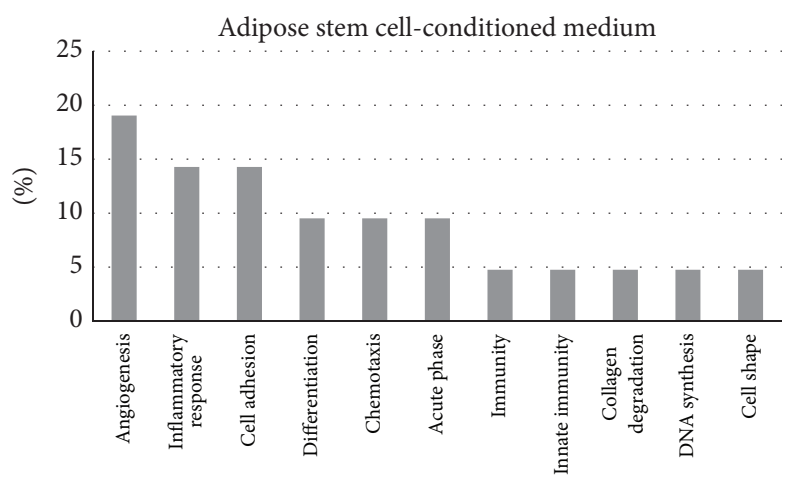

(c1)

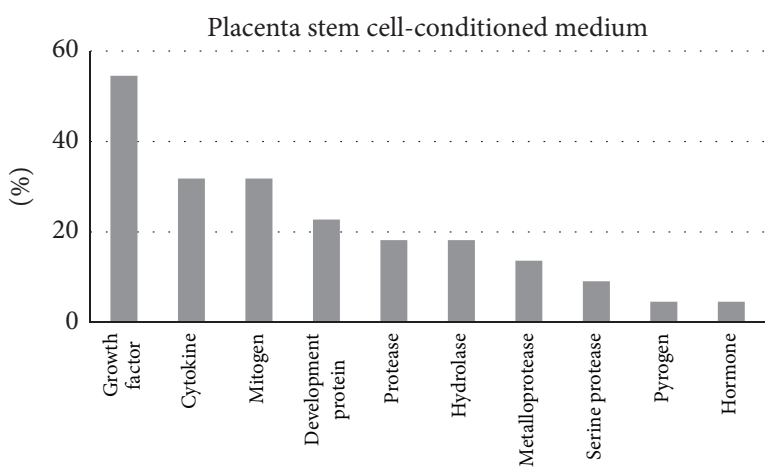

(b2)

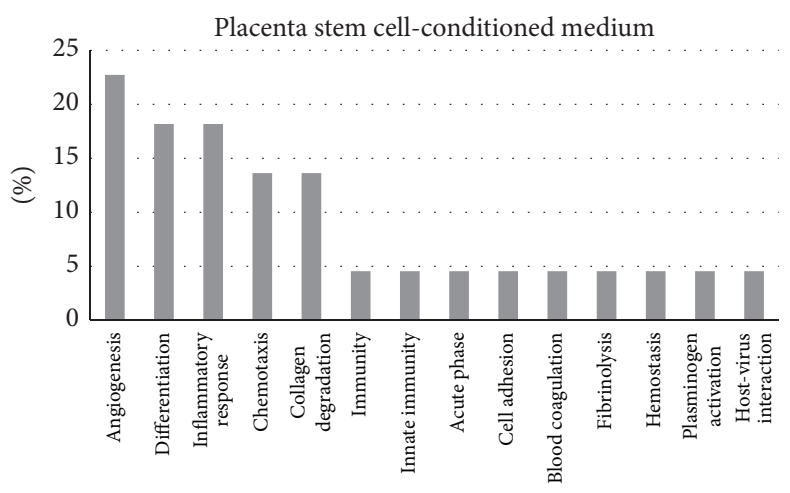

(c2)

FIGURE 3: Characteristics of secretory proteins. 11 proteins were identified in both ASC-CM and PSC-CM, 11 proteins were specific in PSC$\mathrm{CM}$, and 10 proteins were in ASC-CM (a). The molecular function information showed that $52.4 \%$ of total protein types of ASC-CM were growth factor (b1); $54.5 \%$ of PSC-CM was growth factor (b2). The biological process information showed that $19 \%$ of total protein types of ASC-CM had angiogenesis function (c1); 22.7\% of total protein types of PSC-CM had angiogenesis function (c2).

The relatively more active proteins in both kinds of $\mathrm{CM}$ were IL6, IL8, MMP-2, TGF- $\beta$, VEGF, IGF-1, and SDF1 (also known as CXCL12). In the ASC-CM, the unique active proteins were CTGF, FN, TIMP-1, and PEDF (also known as SERPINF1). In the PSC-CM, the unique active proteins were FGF-2, CCL2, FGF-7, MMP-1, and MMP9. This research shows that most of active proteins in the ASC-CM and the PSC-CM are the same. Comparatively, the ASC-CM had more proteins involved in the function of cell adhesion promotion, metalloproteinase inhibition, and plasminogen activator; the PSC-CM had more proteins involved in the function of cell proliferation promotion, differentiation and migration, inflammatory response, and collagen degeneration.
3.3. Antiaging Function in Human Facial Skin. There were no significant differences in the facial indexes between the three groups before injection. 15 days after injection, indexes of Erythema, Melanin, Glossymeter, TEWAmeter, and Corneometer of the ASC-CM group showed improvement compared to the control group. Indexes of Melanin, Glossymeter, TEWAmeter, and Corneometer in PSC-CM group also demonstrated improvement compared to the control group. Only the Melanin index of the ASC-CM group was significantly lower than that of the PSC-CM group (Figure 5). According to ANOVA analysis, there were significant differences among three groups in Erythema index $(F=10.23, p<0.01)$, Melanin index $(F=47.97, p<$ $0.01)$, Glossymeter $(F=85.13, p<0.01)$, TEWAmeter 


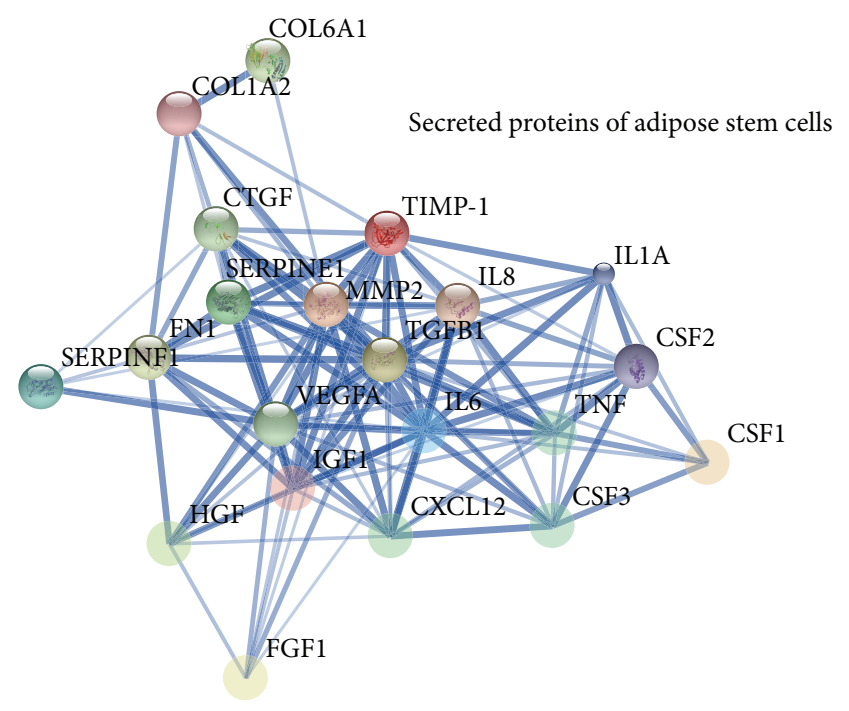

(a)

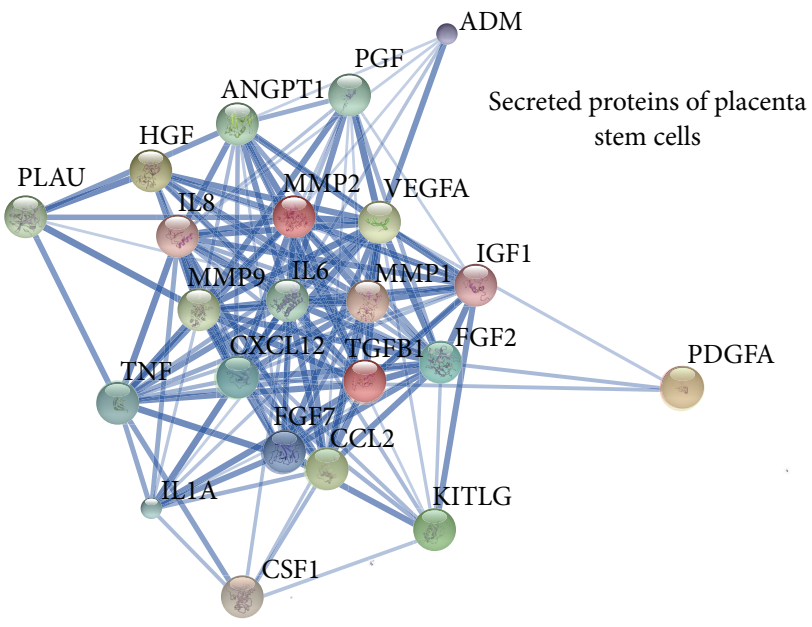

(b)

FIGURE 4: The analysis of protein-protein interaction of secreted proteins of ASC and PSC. The thickness of line represents the strength of evidence. All proteins could interact with others whether in ASC-CM (a) or PSC-CM (b). The relative active proteins in two kinds of CM were IL6, IL8, MMP-2, TGFB1, VEGFA, IGF-1, and CXCL12 (SDF-1). In ASC-CM, the specific active proteins were CTGF, FN, TIMP-1, and SERPINE-1 (PEDF). And in PSC-CM, the specific active proteins were FGF-2, CCL2, FGF-7, MMP-1, and MMP-9.

$(F=13.69, p<0.01)$, and Corneometer $(F=47.42, p<$ $0.01)$, respectively.

\section{Discussion}

In this study, ASCs and PSCs were used as seed cells because adipose tissue and placenta are ideal stem cell sources in daily medical practice. Furthermore, ASCs and PSCs are also ideal substitutes for autologous bone marrow mesenchymal stem cells due to their similar characteristics. In our study, these two kinds of cells demonstrated similar surface markers and multipotency as other mesenchymal stem cells; these results are the same as those of previous studies.

Utilizing CM is a novel cell-free treatment strategy for clinical applications; concentrated CM has partial function of mesenchymal stem cells $[15,16]$. Accumulating evidence indicates that the healing effects of MSCs are mainly related to their unique paracrine properties [17]. In our previous research, ASC-CM was proven to have the ability to promote full-thickness defect skin model healing and human skin laser injury healing [18]. In another research, ASC-CM promoted mouse liver regeneration and increased albumin expression [19]. There has been far less basic and clinical research with PSCs and their CM. In in vitro research, the secretory factors of human chorion-derived stem cells are shown to enhance the activation of human fibroblasts and influence wound healing [20].

hPL was used as the serum-free medium for our cell culture because hPL does not induce an immune response when applied in vivo and provides adequate nutrition for cell culture [21-23]. In this research, hPL did not affect the expression of cell surface markers or the characteristics of multipotent differentiation. Therefore, hPL is an ideal cell culture medium supplement in serum-free and cell-free research.

In MALDI-TOF/TOF analysis, growth factor proteins accounted for $52.4 \%$ and $54.5 \%$ of the total secreted proteins in ASC-CM and PSC-CM, respectively. These growth factors can stimulate cell growth, proliferation, differentiation, and maturation [24, 25]. For example, VEGF and FGF promote the formation of artery and vessel [26, 27]. Cytokines, which are important cell signaling molecules, accounted for $38.1 \%$ and $31.8 \%$ of total secreted proteins in ASC-CM and PSC-CM, respectively. Generally, cytokines are associated with hematopoietic cells and immune system cells; they include chemokine, interferon, interleukin, lymphokine, and tumor necrosis factor $[28,29]$. Cytokines are important in modulating the balance between humoral and cell-based immune responses and could be a neutral term to affect cell proliferation [30]. However, some cytokines promote cell division as growth factors, such as G-CSF, M-CSF, and GMCSF. Mitogen is a chemical substance that stimulates mitosis [31]. Development proteins play an important role in the development of embryos. In addition, many secretory proteins have more than one molecular function. In the analysis of biological processes, we found that proteins involved with angiogenesis and inflammation comprised a major portion in both kinds of CM. However, in the ASC-CM, there were a greater proportion of cell adhesion proteins; in the PSC$\mathrm{CM}$ there was a greater proportion of proteins related to differentiation, chemotaxis, and collagen degradation. This may indicate that ASC-CM is better suited for cell adhesion and that PSC-CM is more appropriate for promoting cell differentiation and chemotaxis.

In the analysis of the protein-protein interaction network, the proteins in the inner layer of the network are considered 


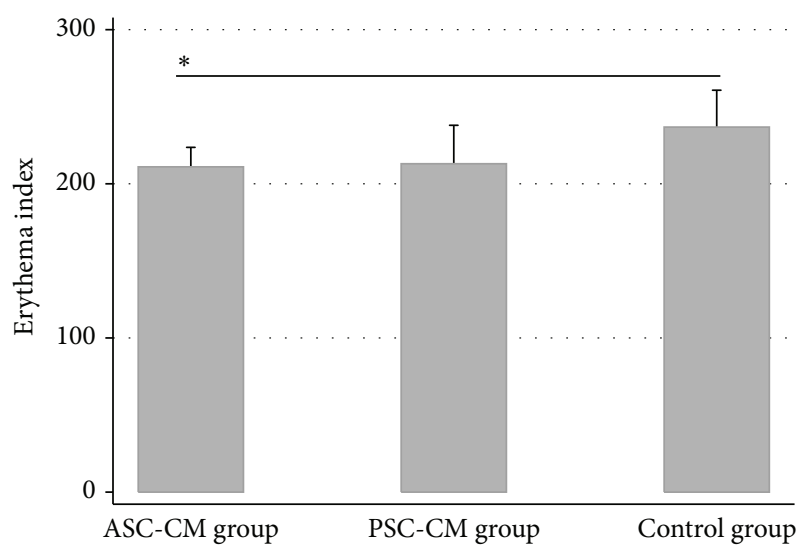

ASC-CM: conditioned medium of adipose stem cell $\quad{ }^{* *} p<0.01$ PSC-CM: conditioned medium of placenta stem cell ${ }^{*} p<0.05$

(a)

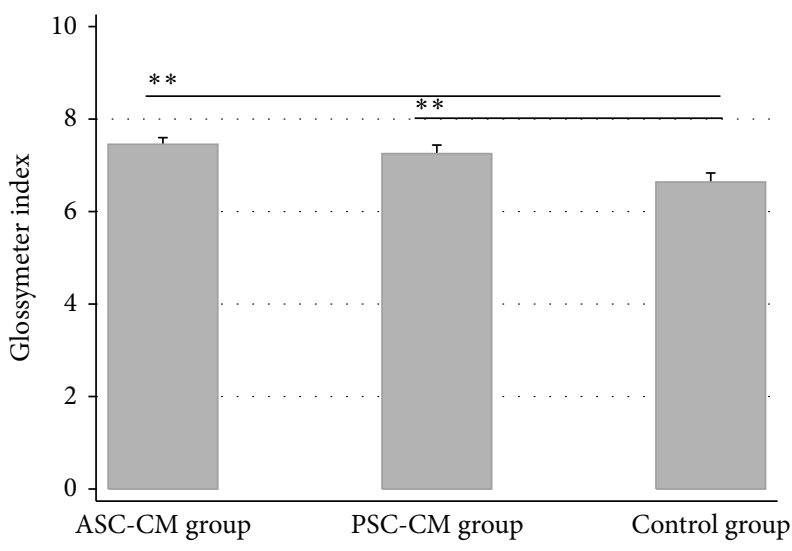

ASC-CM: conditioned medium of adipose stem cell $\quad{ }^{* *} p<0.01$ PSC-CM: conditioned medium of placenta stem cell $\quad{ }^{*} p<0.05$

(c)

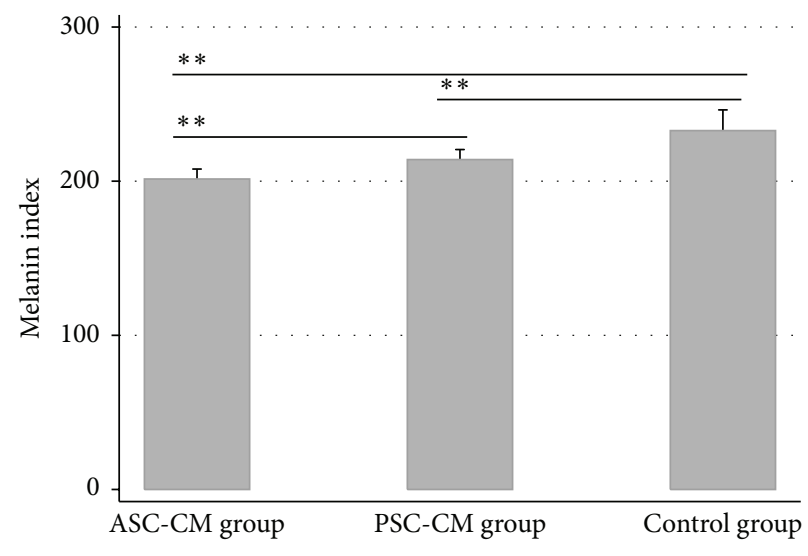

ASC-CM: conditioned medium of adipose stem cell $\quad{ }^{* *} p<0.01$ PSC-CM: conditioned medium of placenta stem cell $\quad{ }^{*} p<0.05$

(b)

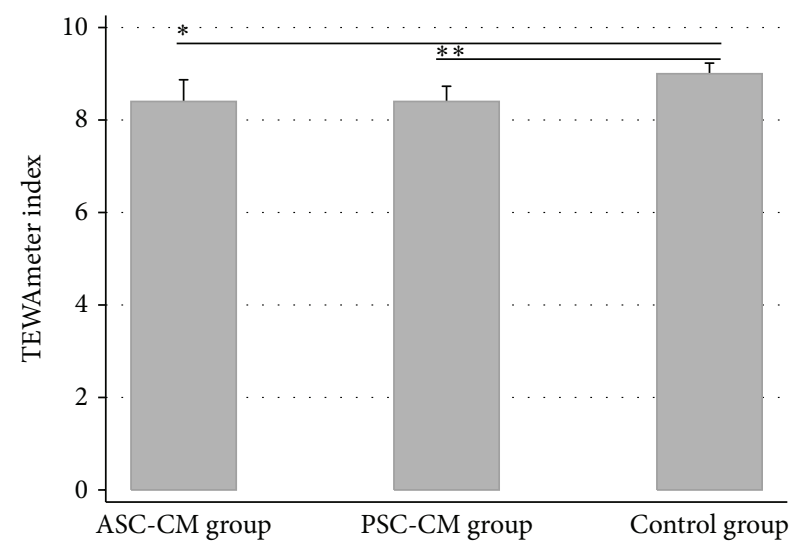

ASC-CM: conditioned medium of adipose stem cell $\quad{ }^{* *} p<0.01$ PSC-CM: conditioned medium of placenta stem cell $\quad{ }^{*} p<0.05$

(d)

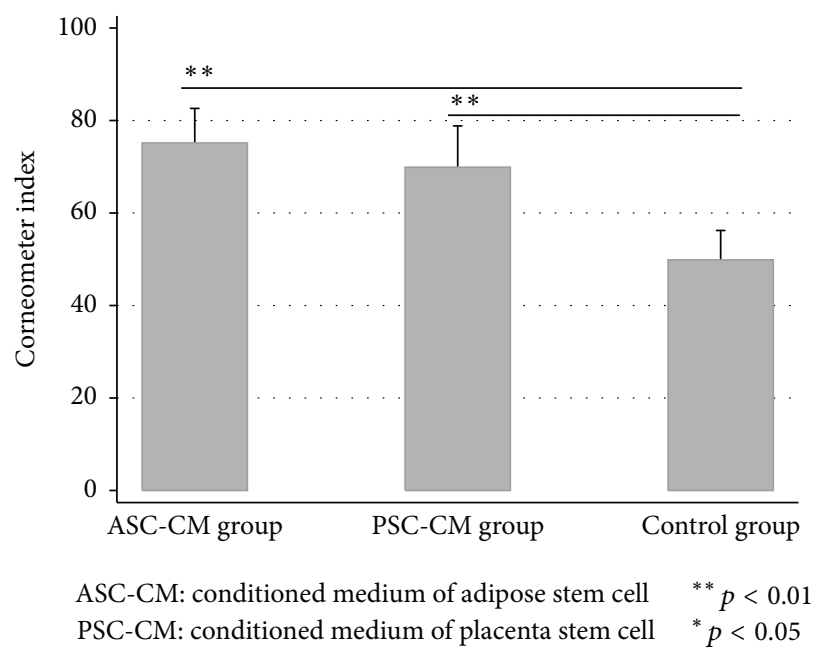

(e)

FIGURE 5: Antiaging functions of ASC-CM and PSC-CM in human facial skin. 15 days after injection, all indexes in ASC-CM group were more improved than those in control group (a-e). All indexes except Erythema in PSC-CM group were more improved than control group (b-e). Only the Melanin index in ASC-CM group was significantly lower than PSC-CM group (b). 
to have more active protein function. The active proteins in both types of CM included IL6, IL8, MMP2, TGFB1, VEGFA, IGF-1, and CXCL12. Interleukins are a group of cytokines that promotes the development and differentiation of $\mathrm{T}$ and B lymphocytes and hematopoietic cells [32]. IL-6 and IL-8 promote hematopoietic stem cell proliferation and differentiation and regulate immune response and chemotaxis $[33,34]$. MMP2 is involved in the breakdown of extracellular matrix, such as during embryonic development, reproduction, and tissue remodeling [35]. TGF-B is a multifunctional protein that controls cells proliferation, differentiation, and other functions [36]. VEGFA is active in angiogenesis, vasculogenesis, and endothelial cell growth [37]. IGF has growthpromoting activity [38]. CXCL12 is strongly chemotactic for lymphocytes and mesenchymal stem cells and plays an important role in angiogenesis [39]. The above indicates that the functions of angiogenesis, cell proliferation, differentiation, inflammatory response, and chemotaxis were found in proteins of both kinds of CM.

The unique active proteins in ASC-CM include CTGF, FN, TIMP-1, and SERPINE-1 (PAI). CTGF is a major connective tissue mitoattractant [40]. Fibronectins promote cell motility, adhesion, and increased wound healing [41]. TIMP1 inhibits metalloproteinase irreversibly by binding to its catalytic zinc cofactor [42]. SERPINE-1 is a type of serine protease inhibitor [43]. Overall, these proteins are more adept at cell adhesion, migration, wound healing, and tissue remodeling.

The unique active proteins in PSC-CM include FGF2, FGF7, CCL2, MMP1, and MMP9. FGF2 and FGF7 play an important role in the regulation of embryonic development, cell survival, cell division, angiogenesis, cell differentiation, and cell migration [44]. CCL2 is a chemotactic factor that attracts monocytes and basophils and augments monocyte antitumor activity [45]. MMP1 and MMP9 cleave types I, II, III, IV, V, VII, and X collagen [46]. The above indicates that proteins unique to PSC-CM are more adept at angiogenesis, cell proliferation, differentiation, cell survival, immunomodulation, and collagen degradation.

Facial aging is a complex process that affects both $3 \mathrm{D}$ shape and textures, such as dryness, coarseness, lost luster, and wrinkles. ASCs are most commonly used in plastic surgery as seed cells. ASC-CM has also been proven to play an important role in the prevention of photoaging dermal cells; our previous study has proven that TGF-b is an essential protein in antiaging. In order to compare the effects of ASC$\mathrm{CM}$ and PSC-CM in skin aging, we injected both CM into facial skin and analyzed the facial skin index. After the injection, both CM greatly improved the facial indexes, such as Erythema and Melanin. ASC-CM and PSC-CM were only different in the index of Melanin. Although the secretory proteins of CM of both cell types were detected, the mechanism of antiaging still requires further inquiry.

\section{Conflict of Interests}

The authors have declared that no competing interests exist.

\section{Authors' Contribution}

Yan Xu and Shilei Guo contributed equally to this paper.

\section{Acknowledgment}

All the authors give thanks to Bingrong Zhou for his valuable experimental help.

\section{References}

[1] O. Zolochevska, J. Shearer, J. Ellis et al., "Human adiposederived mesenchymal stromal cell pigment epithelium-derived factor cytotherapy modifies genetic and epigenetic profiles of prostate cancer cells," Cytotherapy, vol. 16, no. 3, pp. 346-356, 2014.

[2] A. Trounson and C. McDonald, "Stem cell therapies in clinical trials: progress and challenges," Cell Stem Cell, vol. 17, no. 1, pp. 11-22, 2015.

[3] M. Isakson, C. de Blacam, D. Whelan, A. McArdle, and A. J. Clover, "Mesenchymal stem cells and cutaneous wound healing: current evidence and future potential," Stem Cells International, vol. 2015, Article ID 831095, 12 pages, 2015.

[4] H. Munir and H. M. McGettrick, "Mesenchymal stem cell therapy for autoimmune disease: risks and rewards," Stem Cells and Development, vol. 24, no. 18, pp. 2091-2100, 2015.

[5] Y. Zhao, X. Sun, W. Cao et al., "Exosomes derived from human umbilical cord mesenchymal stem cells relieve acute myocardial ischemic injury," Stem Cells International, vol. 2015, Article ID 761643, 12 pages, 2015.

[6] K. Kang, R. Ma, W. Cai et al., "Exosomes secreted from CXCR4 overexpressing mesenchymal stem cells promote cardioprotection via Akt signaling pathway following myocardial infarction," Stem Cells International, vol. 2015, Article ID 659890, 14 pages, 2015.

[7] A. Shabbir, A. Cox, L. Rodriguez-Menocal, M. Salgado, and E. V. Badiavas, "Mesenchymal stem cell exosomes induce proliferation and migration of normal and chronic wound fibroblasts, and enhance angiogenesis in vitro," Stem Cells and Development, vol. 24, no. 14, pp. 1635-1647, 2015.

[8] A. Clabaut, C. Grare, T. Léger, P. Hardouin, and O. Broux, "Variations of secretome profiles according to conditioned medium preparation: the example of human mesenchymal stem cell-derived adipocytes," Electrophoresis, vol. 36, no. 20, pp. 2587-2593, 2015.

[9] C. Gallina, V. Turinetto, and C. Giachino, "A new paradigm in cardiac regeneration: the mesenchymal stem cell secretome," Stem Cells International, vol. 2015, Article ID 765846, 10 pages, 2015.

[10] F. De Francesco, G. Ricci, F. D’Andrea, G. F. Nicoletti, and G. A. Ferraro, "Human adipose stem cells: from bench to bed-side," Tissue Engineering Part B Reviews, vol. 21, no. 6, pp. 572-584, 2015.

[11] H. Busser, M. Najar, G. Raicevic et al., "Isolation and characterization of human mesenchymal stromal cell subpopulations: comparison of bone marrow and adipose tissue," Stem Cells and Development, vol. 24, no. 18, pp. 2142-2157, 2015.

[12] M. S. Oliveira and J. B. Barreto-Filho, "Placental-derived stem cells: culture, differentiation and challenges," World Journal of Stem Cells, vol. 7, no. 4, pp. 769-775, 2015. 
[13] Y. Fukuchi, H. Nakajima, D. Sugiyama, I. Hirose, T. Kitamura, and K. Tsuji, "Human placenta-derived cells have mesenchymal stem/progenitor cell potential," STEM CELLS, vol. 22, no. 5, pp. 649-658, 2004.

[14] J. B. Dame, R. D. Christensen, and S. E. Juul, "The distribution of granulocyte-macrophage colony-stimulating factor and its receptor in the developing human fetus," Pediatric Research, vol. 46, no. 4, pp. 358-366, 1999.

[15] P. Danieli, G. Malpasso, M. C. Ciuffreda et al., "Conditioned medium from human amniotic mesenchymal stromal cells limits infarct size and enhances angiogenesis," Stem Cells Translational Medicine, vol. 4, no. 5, pp. 448-458, 2015.

[16] C. Shen, P. Lie, T. Miao et al., "Conditioned medium from umbilical cord mesenchymal stem cells induces migration and angiogenesis," Molecular Medicine Reports, vol. 12, no. 1, pp. 20 30, 2015.

[17] F. Li and S. Z. Zhao, "Mesenchymal stem cells: potential role in corneal wound repair and transplantation," World Journal of Stem Cells, vol. 6, no. 3, pp. 296-304, 2014.

[18] B.-R. Zhou, Y. Xu, Y. Xu et al., "The effect of conditioned media of adipose-derived stem cells on wound healing after ablative fractional carbon dioxide laser resurfacing," BioMed Research International, vol. 2013, Article ID 519126, 9 pages, 2013.

[19] S. K. Lee, S. C. Lee, and S.-J. Kim, "A novel cell-free strategy for promoting mouse liver regeneration: utilization of a conditioned medium from adipose-derived stem cells," Hepatology International, vol. 9, no. 2, pp. 310-320, 2015.

[20] M. K. Kim, B. F. Seo, K. J. Kim, S.-J. Lee, Y. H. Ryu, and J. W. Rhie, "Secretory factors of human chorion-derived stem cells enhance activation of human fibroblasts," Cytotherapy, vol. 17, no. 3, pp. 301-309, 2015.

[21] C. Y. Li, X. Y. Wu, J. B. Tong et al., "Comparative analysis of human mesenchymal stem cells from bone marrow and adipose tissue under xeno-free conditions for cell therapy," Stem Cell Research \&; Therapy, vol. 6, article 55, 2015.

[22] D. T.-B. Shih and T. Burnouf, "Preparation, quality criteria, and properties of human blood platelet lysate supplements for ex vivo stem cell expansion," New Biotechnology, vol. 32, no. 1, pp. 199-211, 2015.

[23] J. E. Krieger, I. S. Blande, V. Bassaneze et al., "Adipose tissue mesenchymal stem cell expansion in animal serum-free medium supplemented with autologous human platelet lysate," Transfusion, vol. 49, no. 12, pp. 2680-2685, 2009.

[24] X. Zhang, Y. Wang, Y. Gao et al., "Maintenance of high proliferation and multipotent potential of human hair folliclederived mesenchymal stem cells by growth factors," International Journal of Molecular Medicine, vol. 31, no. 4, pp. 913-921, 2013.

[25] D. Qian, J. Gong, Z. He et al., "Bone marrow-derived mesenchymal stem cells repair necrotic pancreatic tissue and promote angiogenesis by secreting cellular growth factors involved in the SDF-1 $\alpha$ /CXCR4 axis in rats," Stem Cells International, vol. 2015, Article ID 306836, 20 pages, 2015.

[26] M. K. Oh, H. J. Park, J. H. Lee, H. M. Bae, and I. S. Kim, "Single chain precursor prohaptoglobin promotes angiogenesis by upregulating expression of vascular endothelial growth factor (VEGF) and VEGF receptor2," FEBS Letters, vol. 589, no. 9, pp. 1009-1017, 2015.

[27] Y. Ito, H. Tsurushima, M. Sato et al., "Angiogenesis therapy for brain infarction using a slow-releasing drug delivery system for fibroblast growth factor 2," Biochemical and Biophysical Research Communications, vol. 432, no. 1, pp. 182-187, 2013.
[28] C. M. Schürch, C. Riether, and A. F. Ochsenbein, "Cytotoxic $\mathrm{CD}^{+} \mathrm{T}$ cells stimulate hematopoietic progenitors by promoting cytokine release from bone marrow mesenchymal stromal cells," Cell Stem Cell, vol. 14, no. 4, pp. 460-472, 2014.

[29] M. C. Búfalo, A. P. Bordon-Graciani, B. J. Conti, M. de Assis Golim, and J. M. Sforcin, "The immunomodulatory effect of propolis on receptors expression, cytokine production and fungicidal activity of human monocytes," Journal of Pharmacy and Pharmacology, vol. 66, no. 10, pp. 1497-1504, 2014.

[30] P. Li, R. Spolski, W. Liao, and W. J. Leonard, "Complex interactions of transcription factors in mediating cytokine biology in $\mathrm{T}$ cells," Immunological Reviews, vol. 261, no. 1, pp. 141-156, 2014.

[31] J. S. C. Arthur and S. C. Ley, "Mitogen-activated protein kinases in innate immunity," Nature Reviews Immunology, vol. 13, no. 9, pp. 679-692, 2013.

[32] D. Szklarczyk, A. Franceschini, S. Wyder et al., "STRING v10: protein-protein interaction networks, integrated over the tree of life," Nucleic Acids Research, vol. 43, no. 1, pp. D447-D452, 2015.

[33] G.-L. Lee, Y.-W. Chang, J.-Y. Wu et al., "TLR 2 induces vascular smooth muscle cell migration through cAMP response element-binding protein-mediated interleukin-6 production," Arteriosclerosis, Thrombosis, and Vascular Biology, vol. 32, no. 11, pp. 2751-2760, 2012.

[34] Y. Ruan, X. Ji, M. Wen, X. Zhu, and X. Fu, "Interleukin 8 enhances the immune response of ducks to avian influenza vaccine," Acta Virologica, vol. 58, no. 4, pp. 356-358, 2014.

[35] M. Ferrer, H. Rodriguez, L. Zara, Y. Yu, W. Xu, and R. Oko, "MMP2 and acrosin are major proteinases associated with the inner acrosomal membrane and may cooperate in sperm penetration of the zona pellucida during fertilization," Cell and Tissue Research, vol. 349, no. 3, pp. 881-895, 2012.

[36] A. Vaidya and V. P. Kale, "TGF- $\beta$ signaling and its role in the regulation of hematopoietic stem cells," Systems and Synthetic Biology, vol. 9, no. 1, pp. 1-10, 2015.

[37] N. M. Kofler and M. Simons, "Angiogenesis versus arteriogenesis: neuropilin 1 modulation of VEGF signaling," F1000Prime Reports, vol. 7, article 26, 2015.

[38] C. Livingstone, "Insulin-like growth factor-I (IGF-I) and clinical nutrition," Clinical Science, vol. 125, no. 6, pp. 265-280, 2013.

[39] J. Shi, Y. Wei, J. Xia et al., "CXCL12-CXCR4 contributes to the implication of bone marrow in cancer metastasis," Future Oncology, vol. 10, no. 5, pp. 749-759, 2014.

[40] A. Dendooven, K. G. Gerritsen, T. Q. Nguyen, R. J. Kok, and R. Goldschmeding, "Connective tissue growth factor (CTGF/CCN2) ELISA: a novel tool for monitoring fibrosis," Biomarkers, vol. 16, no. 4, pp. 289-301, 2011.

[41] J. E. Schwarzbauer and D. W. DeSimone, "Fibronectins, their fibrillogenesis, and in vivo functions," Cold Spring Harbor Perspectives in Biology, vol. 3, no. 7, Article ID a005041, 2011.

[42] S. Du, G. Mao, T. Zhu, Z. Luan, Y. Du, and H. Gu, "TIMP1 in conditioned media of human adipose stromal cells protects neurons against oxygen-glucose deprivation injury," Neuroscience Letters, vol. 584, pp. 56-59, 2015.

[43] S. Yasar Yildiz, P. Kuru, E. Toksoy Oner, and M. Agirbasli, "Functional stability of plasminogen activator inhibitor-1," The Scientific World Journal, vol. 2014, Article ID 858293, 11 pages, 2014.

[44] M. Inchovska, V. Ogneva, and Y. Martinova, "Role of FGF1, FGF2 and FGF7 in the development of the pancreas from control and streptozotocin-treated hamsters," Cell Proliferation, vol. 39, no. 6, pp. 537-550, 2006. 
[45] D. Bauer, N. Redmon, E. Mazzio et al., "Diallyl disulfide inhibits TNF $\alpha$ induced CCL2 release through MAPK/ERK and NFKappa-B signaling," Cytokine, vol. 75, no. 1, pp. 117-126, 2015.

[46] S. R. Van Doren, "Matrix metalloproteinase interactions with collagen and elastin," Matrix Biology, vol. 44-46, pp. 224-231, 2015. 

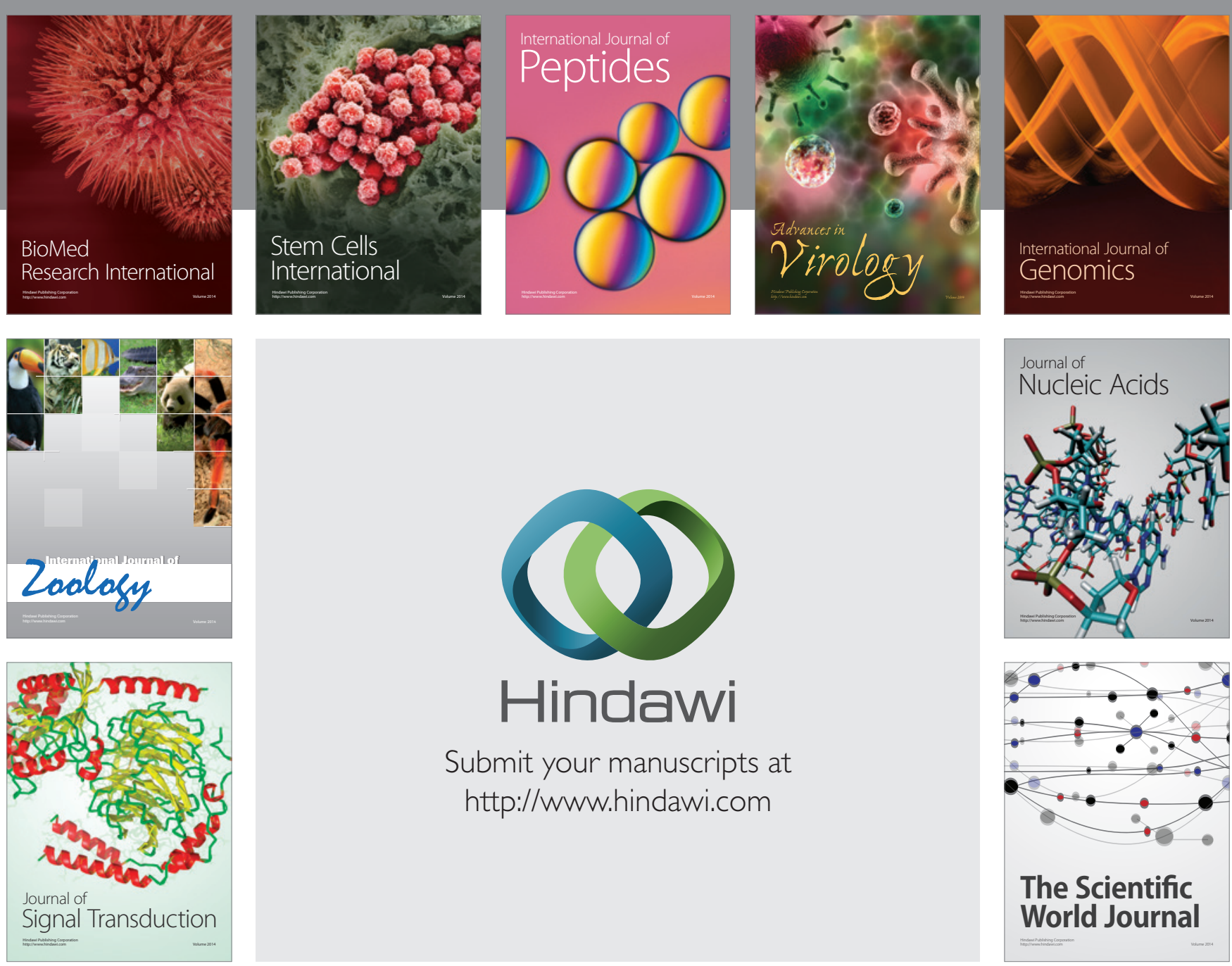

Submit your manuscripts at

http://www.hindawi.com
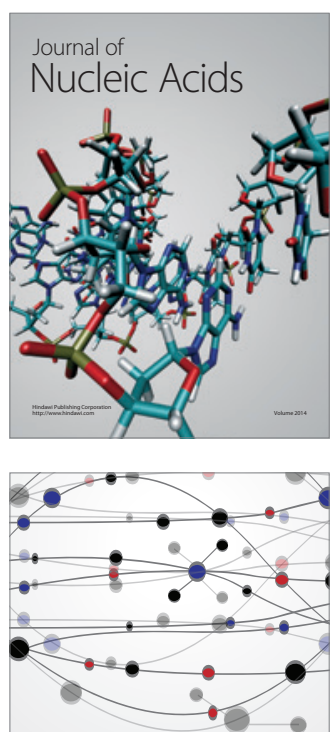

The Scientific World Journal
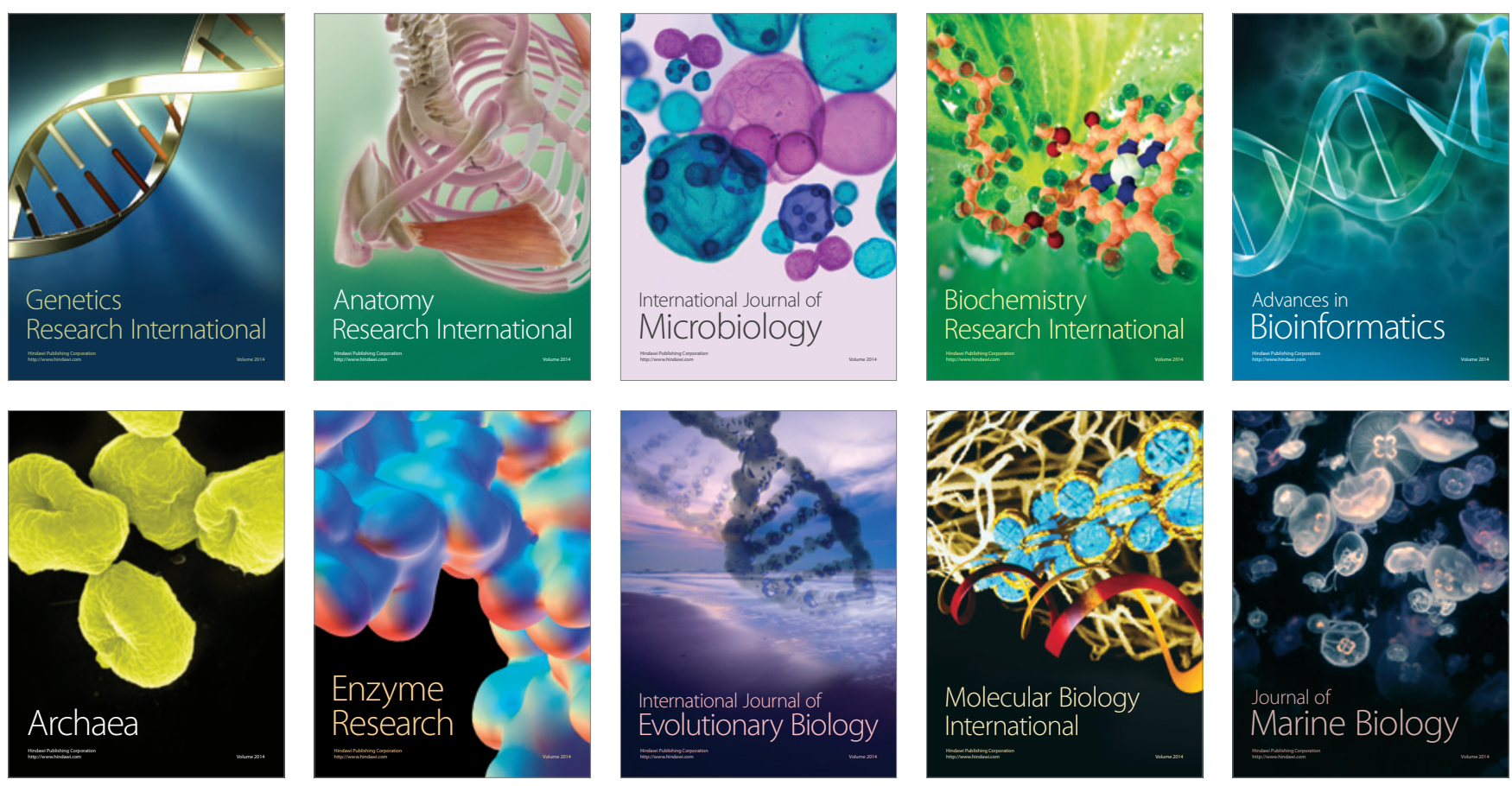